EGU2020-4432

https://doi.org/10.5194/egusphere-egu2020-4432

EGU General Assembly 2020

(c) Author(s) 2021. This work is distributed under

OAuthor(s) 2021. This work is distributedunder

(c) (i)

\title{
Measuring gravity changes for decades
}

Michel Van Camp iD ${ }^{1}$, Olivier de Viron (D) ${ }^{2}$, Bruno Meurers iD $^{3}$, and Olivier Francis ${ }^{4}$

${ }^{1}$ Royal Observatory of Belgium, Seismology-Gravimetry, Brussels, Belgium (mvc@oma.be)

University of La Rochelle, Littoral, Environnement et Sociétés LIENSs

3University of Vienna, Department of Meteorology and Geophysics

${ }^{4}$ University of Luxembourg, Faculty of Science, Technology and Communication

Being sensitive to any phenomena associated with mass transfer, terrestrial gravimetry allows the monitoring of many phenomena at the $10^{-10} \mathrm{~g}$ level $\left(1 \mathrm{~nm} / \mathrm{s}^{2}\right)$ such as Earth tides, groundwater content, tectonic deformation, or volcanic activity. This sensitivity is richness, but also a source of problems because data interpretation requires separating the signatures from the different sources, including possible measurement artefacts associated with high precision. Separating the signal from a given source requires a thorough knowledge of both the instrument and the phenomena.

At the Membach geophysical laboratory, Belgium, the same superconducting gravimeter has monitored gravity continuously for more than 24 years. Together with 300 repeated absolute gravity measurements and environmental monitoring, this has allowed us to reach an unprecedented metrological knowledge of the instrument and of its sensitivity to hydrological and geophysical signals.

Separation is possible whenever the phenomena exhibit distinct time/frequency signatures, such as (pseudo)periodic phenomena or long-term processes, so that the signatures from other sources average out by stacking. For example, when performing repeated gravity measurements to evidence slow tectonic deformation, the easiest way to mitigate hydrologica effects is to accumulate measurements for many years, at the same epoch of the year: the impact of seasonal variations is then minimized, and the interannual variations cancel out. Using 10 repeated absolute gravity campaigns at the same epoch of the year, we showed that the gravity rate of change uncertainty reaches on average 3-4 nm/s²yr. Concurrently, using superconducting gravimeter time series longer than 10 years, we also investigated the time variations of tidal parameters.

It is also possible to separate phenomena by observing them by both gravity and some other techniques, with a different transfer function. By using 11 year-long times series from the gravimeter and soil moisture probes, and by stacking the observations, we measured directly the groundwater mass loss by evapotranspiration in the forest above the laboratory of Membach. Always with a precision better than $1 \mathrm{~nm} / \mathrm{s}^{2}(<=>2.5 \mathrm{~mm}$ of water), we also monitored ground partial saturation dynamics and combining the gravity data with a weather radar allowed measuring convective precipitation at a scale of up to $1 \mathrm{~km}^{2}$.

Extracting and interpreting those elusive signals could only by achieved throughout multi-instrumentation, multi-disciplinary collaborative studies, and 25 years of hard work

How to cite: Van Camp, M., de Viron, O., Meurers, B., and Francis, O.: Measuring gravity changes for decades, EGU General Assembly 2020, Online, 4-8 May 2020, EGU2020-4432, https://doi.org/10.5194/egusphere-egu2020-4432, 2020

Display materials

Display file

\section{Comments on the display material}

AC: Author Comment | CC: Community Comment $\mid \square$ Report abuse

Display material version 2 - uploaded on 07 May 2020, no comments

Cosmetic

Display material version 1 - uploaded on 06 May 2020, no comments 